\title{
A coupled core-mantle evolution: review and future prospects
}

Takashi Nakagawa ${ }^{1,2}$ (D)

\begin{abstract}
In this review, I provide the current status and future prospects for the coupled core-mantle evolution and specifically summarize the constraints arising from geomagnetism and paleomagnetism on the long-term secular variations of the geomagnetic field. The heat flow across the core-mantle boundary (CMB) is essential for determining the best-fit scenario that explains the observational data of geomagnetic secular variations (e.g., onset timing of the inner core growth, geomagnetic polarity reversals, and westward drift) and should include the various origins of the heterogeneous structures in the deep mantle that have affected the heat transfer across the coremantle boundary for billions of years. The coupled core-mantle evolution model can potentially explain the onset timing of the inner core and its influence on the long-term geomagnetic secular variations, but it is still controversial among modeling approaches on the core energetics because the paleomagnetic data contains various uncertainties. Additionally, with the coupled core-mantle evolution model in geodynamo simulations, the frequency of the geomagnetic polarity reversals can be explained with the time variations of the heat flow across the CMB. Additionally, the effects of the stable region in the outermost outer core to the magnetic evolution are also crucial but there would be still uncertain for their feasibility.

However, despite this progress in understanding the observational data for geomagnetic secular variations, there are several unresolved issues that should be addressed in future investigations: (1) initial conditions - starting with the solidification of the global magma ocean with the onset timing of plate tectonics and geodynamo actions and (2) planetary habitability-how the dynamics of the Earth's deep interior affects the long-term surface environment change that has been maintained in the Earth's multisphere coupled system.
\end{abstract}

Keywords: Geomagnetic field, Earth's core, Deep mantle, Long-term evolution

\section{Introduction}

The ultimate goal for revealing the deep planetary interior is to understand why the Earth may experience both plate tectonics and a main geomagnetic field as a result of the activities of the deep planetary interior (e.g., Stevenson et al. 1983). Plate tectonics is driven by convective actions in the deep mantle, and a geomagnetic field is generated by the convective action of the metallic core driving the geodynamo (e.g., Lister and Buffett 1995). Understanding the dynamical processes across the

Correspondence: takashi.geodynamics@gmail.com

'Division of Earth and Planetary Sciences, The University of Hong Kong, Pokfulam Road, Pokfulam, Hong Kong

${ }^{2}$ Department of Earth and Planetary System Science, Hiroshima University, Higashi-Hiroshima, Japan

\section{Springer Open}

Earth's deep interior is essential for giving a consistent scenario on its long-term evolution and the habitability of planetary surfaces (e.g., Foley and Driscoll 2016), but there is still a lack of information on these processes. Several reasons for this information deficit are described below: (1) Earth's deep interior cannot see itself directly, but it can be visualized with helps of geophysical observations, high pressure material science, and geochemical analyses; (2) theoretical and numerical modeling augments interpretations from data analyses of geophysical observations; and (3) various interactions across boundaries within the modeling processes should be understood to reveal the geophysical/geochemical/geological processes found by the observations. Particularly, the interactions of the Earth's various dynamic systems are 
important for understanding the habitability of Earthlike rocky planets because the climate condition is essential for the planetary habitability. The climate condition can be described as the variations of atmospheric compositions such as the greenhouse gasses that can be supplied with the volcanic degassing from the deep planetary interior (e.g., Ernst and Youbi 2017.). Thus, as quoted above, the interaction of the Earth's various systems is crucial for revealing why the Earth can be characterized by the habitable planet.

In this review, I introduce the current understanding and accomplishments for the long-term evolution of the Earth's deep interior in terms of numerical/theoretical modeling approaches that explain observational data and their interpretations; additionally, I address topics on short-term evolution such as geomagnetic polarity reversals and the westward drift. Although this review may include bias, its ultimate purpose is to point out the issues arising from observational data concerning the evolution, structure, and dynamics of the Earth's deep interior as well as evolution processes ranging from the early magma ocean to the present-day Earth.

\section{Observational constraints}

In this section, two important geomagnetism and paleomagnetism constraints for determining the appropriate scenario on the coupled core-mantle evolution are introduced: (1) long-term geomagnetic field intensity and its implication for the inner core growth and structure of the outermost outer core and (2) geomagnetic secular variations in thermal coupling across the coremantle boundary, which are geomagnetic polarity reversals and non-dipolar field generation.

\subsection{Long-term variations of the intensity of the geomagnetic field: inner core growth and the outermost core}

Long-term variations of the intensity of the geomagnetic field inferred from the paleomagnetic measurement aims can be used to determine when the inner core starts nucleation, which likely corresponds to a sudden change in paleomagnetic intensity (e.g., Tarduno et al. 2006). This concept has been proposed for the timing of the transition from purely thermal convection to thermal and chemical convection in the Earth's core, because the chemical convection caused by the light element release with the inner core growth is an additional driving force of the convection in the Earth's core (e.g., Stevenson et al. 1983). Figure 1 shows the schematic illustration of the relationship between a sudden change in the paleointensity and the transition of the convective physics in the Earth's core, which switches from purely thermal convection to thermal and chemical convection. Due to progress in paleointensity measurements

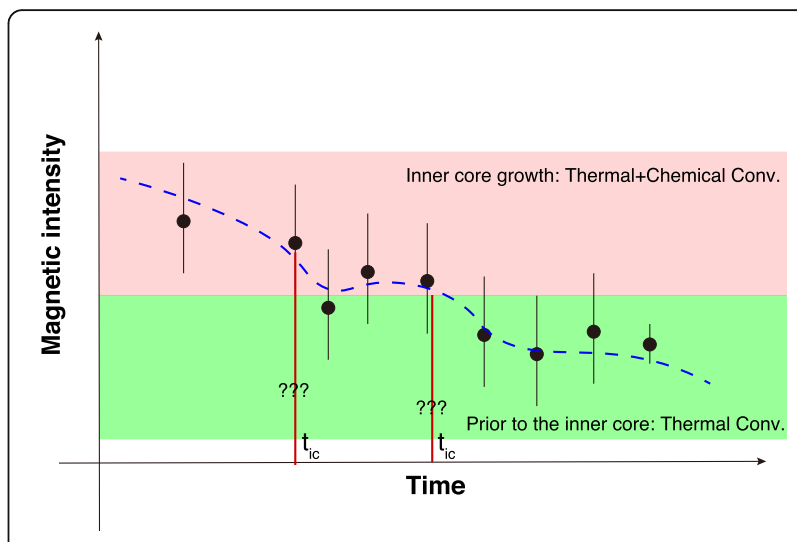

Fig. 1 Schematic illustrations of the interpretations for the onset of the inner core growth used in paleomagnetic data. There are some uncertainties in determining the onset timing of the inner core growth from the paleomagnetic data; this is because it is difficult to determine the timing of the sudden change of the magnetic field intensity that corresponds to the transition of driving mechanisms of the core convection from a purely thermal convection to a combined thermal and chemical convection

facilitated by considerable technological improvements, the onset timing of the inner core growth is inferred as the younger age of the inner core (e.g., Biggin et al. 2015); this is consistent with the theoretical model of the age of the inner core, which may be $\sim 1 \mathrm{Ga}$ (Labrosse et al. 2001). However, the age of the inner core inferred from the paleomagnetism includes large uncertainties ranging from 0.5 to $2.5 \mathrm{Ga}$ (Biggin et al. 2015; Tarduno et al. 2015); these uncertainties are caused by the quality of the samples (strongly affected by weathering, thunder, and tectonics metamorphism) even if the measurement techniques are greatly improved (Smirnov et al. 2016). Despite these uncertainties, a sudden change in the paleointensity of the geomagnetic field can be still useful in constraining the onset timing of the inner core growth.

\subsection{Short-term variations of geomagnetic fields: spatial patterns and core-mantle coupling}

The time variations of the spatial pattern of the geomagnetic field and its origin are interesting for interpreting the dynamics of the Earth's core, including the variations of the non-dipolar magnetic field (westward drift; e.g., Yukutake and Shimizu 2015) and geomagnetic polarity reversals (Courtillot and Besse 1987). These researches are generally quoted that both geomagnetic events are generated as a result of the various styles of the coremantle coupling processes.

On the spatial variations of the geomagnetic field, the secular variations of the non-dipolar geomagnetic field can be decomposed into its drifting and standing parts (e.g., Yukutake and Shimizu 2015). The drifting part is known as $\sim 0.3^{\circ} /$ year from west to east (westward drift; 
e.g., Bullard et al. 1950), which predicted that the silicate mantle and metallic core would be coupled with a certain mechanism. The standing part is likely to stay a certain region corresponding to the large-scale seismic anomalies in the deep mantle, which also predicted a certain mechanism of the core-mantle coupling (e.g., Yukutake and Shimizu 2016). The physics behind those parts of the non-dipolar geomagnetic field can be interpreted by core-mantle thermal coupling (e.g., Bloxham et al. 1989) and/or by core-mantle topographic coupling (e.g., Yoshida and Hamano 1993) for the drifting and standing parts of non-dipolar fields. For the thermal and topography anomalies, mantle convection and plate tectonics may play essential roles in both coupling mechanisms (Nakagawa and Tackley 2008; Deschamps et al. 2018). On the long-term history of the paleomagnetic data, the geomagnetic polarity reversals in dipolar fields may be related to the core-mantle coupling processes (Larson and Olson 1991; Courtillot and Olson 2007; Biggin et al. 2012). The frequency of the polarity reversals may be correlated with the plume events that cause the formation of Large Igneous Provinces (LIPs).

To understand the relationship between large-scale events caused by the mantle dynamics and geomagnetic secular variations, the dynamics of the deep mantle should be comprehensively understood. Seismic tomographic images are the way for revealing the dynamics in the deep mantle (e.g., Ritsema et al. 2011). Tomographic images generally indicate two large slow velocity anomalies located beneath the Pacific and Africa, which are referred to as 'Large Low-Shear Velocity Provinces' (LLSVPs). Explanations of the origins of these largescale seismic anomalies are still controversial because the resolution of current seismic imaging is not sufficient. For determining the origins of such anomalies, the anti-correlation between shear wave anomalies and bulk sound velocity anomalies should be satisfied. This suggests that the shear wave anomalies are likely to represent the thermal effects of the seismic anomalies, while the bulk sound anomalies may be indicated in the density anomalies. In the LLSVPs, the slower shear anomalies correspond to the faster anomalies of the bulk sound velocity. This dynamic may suggest that the origins of these anomalies may be simultaneously caused by thermal and compositional effects (e.g., Ishii and Tromp 1999). Geodynamics modeling investigations have tested the hypothesis of the origin of the deep mantle heterogeneity (e.g., Deschamps et al. 2011). With the adjoint model of seismic tomography and convective dynamics in the deep mantle, the post-perovskite phase may potentially explain the large-scale anomalies in the deep mantle (e.g., Koelemeijer et al. 2018). However, since the post-perovskite phase may not appear in the slow seismic anomalies (e.g., Nakagawa and Tackley 2005b), the interpretation of the adjoint model may be somewhat doubtful. In contrast, spectral analysis and its correlation between numerical modeling and seismic imaging indicate that the thermal and chemical origins can explain some of the constraints (anti-correlation between the bulk sound and shear wave anomalies and the horizontal length-scale) of heterogeneous structures (Tackley, 2002; Nakagawa et al. 2010; Deschamps et al. 2011; Jones et al. 2020). The "tomographic filter" was introduced to improve the geodynamics interpretations in the deep mantle from the seismic tomographic images (e.g., Ritsema et al. 2007), but the geodynamics interpretations are not well improved because, again, interpretations of the dynamics in the deep mantle are still not consistent with the requirements from the thermal and chemical conditions of the deep mantle mineralogy, using the adjoint geodynamics-seismic model based on the tomographic filtering. More efforts should be made to improve the seismic imaging in the deep mantle and thus improve interpretations of the dynamics in the Earth's deep interior.

\section{Importance of the heat transfer across the core- mantle boundary (CMB)}

In the previous sections, several observational constraints for revealing the coupled evolution of the core and mantle were discussed. To model and determine the consistent evolution scenario for the coupled coremantle evolution as one system, the heat transfer across the $\mathrm{CMB}$ is the most significant quantity to reveal the coupled evolution between the silicate mantle and metallic core (e.g., Buffett et al. 1996; Labrosse et al. 1997). As discussed above, the heat transfer across the CMB strongly affects the evolution of the geomagnetic field and inner core size, and the spatial pattern of the geomagnetic secular variations. In this section, I introduce the current knowledge on the amplitude and spatial pattern of the heat flow across the CMB in terms of the long-term and short-term evolution of the Earth's core.

\subsection{A range of the heat flow across the CMB: long-term evolution}

For the long-term evolution of the heat flow across the $\mathrm{CMB}$, the heat transfer of the mantle convection is essential. This is because the timescale of the mantle convection is controlled by plate tectonics, which occurs at timescales of millions and billions of years. In theoretical modeling of the thermodynamics of the thermal and magnetic evolution of the Earth's core that is simplified for the heat transfer across the core-mantle boundary; the time variations caused by the mantle convection and plate tectonics should be considered for the long-term evolution (e.g., Labrosse 2015). 
The amplitude of the heat transfer across the coremantle boundary is, again, an important piece of information that is needed to understand the long-term evolution processes of the Earth's core. As indicated in a recent review article (Lay et al. 2008), the heat flow across the core-mantle boundary may range from 8 to $15 \mathrm{TW}$ at the present. Looking at the heat budget across the entire Earth show in Table 1, the heat flow across the oceanic lithosphere is approximately $32 \mathrm{TW}$ and heat production in the silicate mantle is approximately 20 TW including the effects of the continental lithosphere that is around $\sim 7$ TW (e.g., Jaupart et al. 2007). Hence, the heat transfer across the core-mantle boundary ranges from 25 to $50 \%$ of the heat transfer of plate tectonics.

More recently, the heat flow across the core-mantle boundary inferred from the deep mantle melting and thermal conductivity measurement of the metallic core has been required for nearly the upper-bound value to maintain the thermal and chemical convection of the Earth's core (Labrosse et al. 2007; Gomi et al. 2013). To find the thermal convection in the Earth's core, the heat flow across the CMB should exceed the isentropic heat flow (adiabatic heat flow). The thermal convection in the Earth's core is the essential mechanism for the geodynamo actions prior to the inner core growth (Labrosse 2015; Davies 2015).

For finding the better estimate of the heat flow across the $\mathrm{CMB}$, the thermal conductivity of metallic iron seems to be crucial (Gomi et al. 2013). However, the value of the thermal conductivity of metallic iron has a high uncertainty ranging from 16 to $220 \mathrm{~W} / \mathrm{m} / \mathrm{K}$ (Konôpková et al. 2016; Ohta et al. 2016). From Gomi et al. (2013), the heat flow across the core-mantle boundary that may maintain the thermal convection in the Earth's core is required to have more than $11 \mathrm{TW}$ of heat flow across the core-mantle boundary at minimum. The high thermal conductivity of the Earth's core may have a high isentropic heat flow; hence, a sufficient amount of heat flow that exceeds the isentropic heat flow is required to maintain the convective actions in the Earth's core. In summary, incorporating the range quoted by the literature (Lay et al. 2008), the current constraint on the heat flow across the CMB is likely to range $11 \mathrm{TW}$ to $15 \mathrm{TW}$ at the present time.

\subsection{Spatial pattern of the CMB heat flux: short-term evolution}

The other importance of the heat flow across the CMB is the spatial pattern and its role in the geomagnetic secular variations (Bloxham et al. 1989; Olson 2016). As quoted the previous section ('Observational Constraints'), the secular variations of the spatial pattern of the geomagnetic field (geographical path of the polarity reversals and westward drift) may be interpreted by the geodynamo action with the core-mantle thermal coupling. There are a few good review articles concerning the core-mantle thermal coupling in the geodynamo modeling (Olson 2016; Wicht and Sanchez 2019). In this section, I introduce the summary of those reviews.

As in numerical geodynamo simulations, the spatial pattern of the heat flux across the CMB has been imposed as the heterogeneous boundary condition, being converted from the seismic tomography in the deep mantle (Glatzmaier et al. 1999; Olson and Christensen 2002). Geodynamo simulations with the heterogeneous boundary condition have indicated the spatial patterns and variations of the geomagnetic field generation such as the moving path of the geomagnetic pole as a function of time (e.g., Glatzmaier et al. 1999). Additionally, the heterogeneity pattern of the inner core boundary may also affect the spatial pattern of the heat flux across the core-mantle boundary (Gubbins et al. 2011; Aubert et al. 2013), which can explain the seismological observations of the heterogenous structure near the uppermost inner core (Deuss 2014; Pejic et al. 2017; Burdick et al. 2019).

In this type of geodynamo simulation, the heat flux at the CMB is imposed as the top thermal boundary condition, which is converted from the seismic tomography taken near the bottom of the mantle (e.g., Olson and Christensen 2002). The conversion concept is that the seismic anomalies are purely explained by the thermal effect; however, in an accomplishment of the numerical mantle convection simulations, including the findings of detailed seismological analyses and mineral physics

Table 1 Heat budget across the Earth's deep interior. Model estimates are taken from Nakagawa and Tackley (2012); Observational constraints are taken from Jaupart et al. (2007). The heat production rate is indicated after excluding the heat production of the continental crust which is typically 7 TW (see Jaupart et al. 2007). The cooling rate at the core-mantle boundary is represented as the convective cooling rate in the whole mantle

\begin{tabular}{lll}
\hline & Model & Observational constraints \\
\hline Surface heat flow across the oceanic lithosphere & $\sim 35$ TW & 32 TW \\
Heat flow across the CMB & 12 TW & 8 TW \\
Heat production in the silicate mantle (excl. the continental crust) & $12.5-28.5$ TW & 13 TW \\
Cooling rate at the core-mantle boundary & $\sim 70$ K/Gyrs & $118 \mathrm{~K} / \mathrm{Gyrs}$ \\
\hline
\end{tabular}


constraints, the heat flux across the CMB was not simply correlated with the seismic anomalies. This indicates a non-linear relationship between seismic anomalies and the heat flux across the CMB (Nakagawa and Tackley 2008). Hence, the relationship is complicated since the seismic anomalies may be explained by various complexities. Amit and Choblet (2012) incorporated non-linear effects while converting the heat flux across the $\mathrm{CMB}$ boundary from the seismic anomalies inferred from Nakagawa and Tackley (2008); however, the morphology of the magnetic field, including the non-linear effect, was not considerably different from the simple linear scaling between the seismic anomalies and heat flux across the CMB. Despite these small effects combined with the complexities of the deep mantle heterogeneity, the complexities in mantle convection, including the plate motions and deep mantle heterogeneity, plays an important role in the geographical paths of polarity reversals (e.g., Olson et al. 2013, 2015).

\section{A coupled core-mantle evolution model: long- term evolution}

In this section, a brief review on the coupled core-mantle evolution modeling is introduced. This modeling approach can interpret the long-term evolution of the intensity of the geomagnetic field over billions of years. Unlike the previous section, which exclusively addresses the short-term evolution of core-mantle coupling, the long- term evolution is only addressed. As performed in various investigations (Stevenson et al. 1983; Nakagawa and Tackley 2004; Nakagawa and Tackley, 2005a; Nakagawa and Tackley 2010), the model concept is shown in Fig. 2. As indicated in Fig. 2b, the heat flux should be continuous across the $\mathrm{CMB}$, which means that the heat flux must be identical at just below and above the boundary. Hence, the mantle convection model may provide the heat flux across the bottom boundary to the energetics of the core convection (Fig. 2c). For mantle convection models, there are two choices used to compute the heat flow across the CMB: Parameterized convection or full simulations. For more detail, in this section, I first introduce the theory of the core evolution in the energetics of the core convection so that the inner core growth and magnetic field intensity can be computed. Next, the accomplishments of the coupled core-mantle evolution in two types of the mantle convection approach (parameterized and full fluid dynamics simulation), which is incorporated into the energetics of the core convection, are provided.

\subsection{Energetics of the Earth's core: inner core growth and magnetic field generation}

In this section, the energetics of the Earth's core are described because they represent a common physics for both mantle convection approaches in the coupled coremantle evolution modeling. Being based on the arguments in Labrosse (2015) and Takehiro and Sasaki

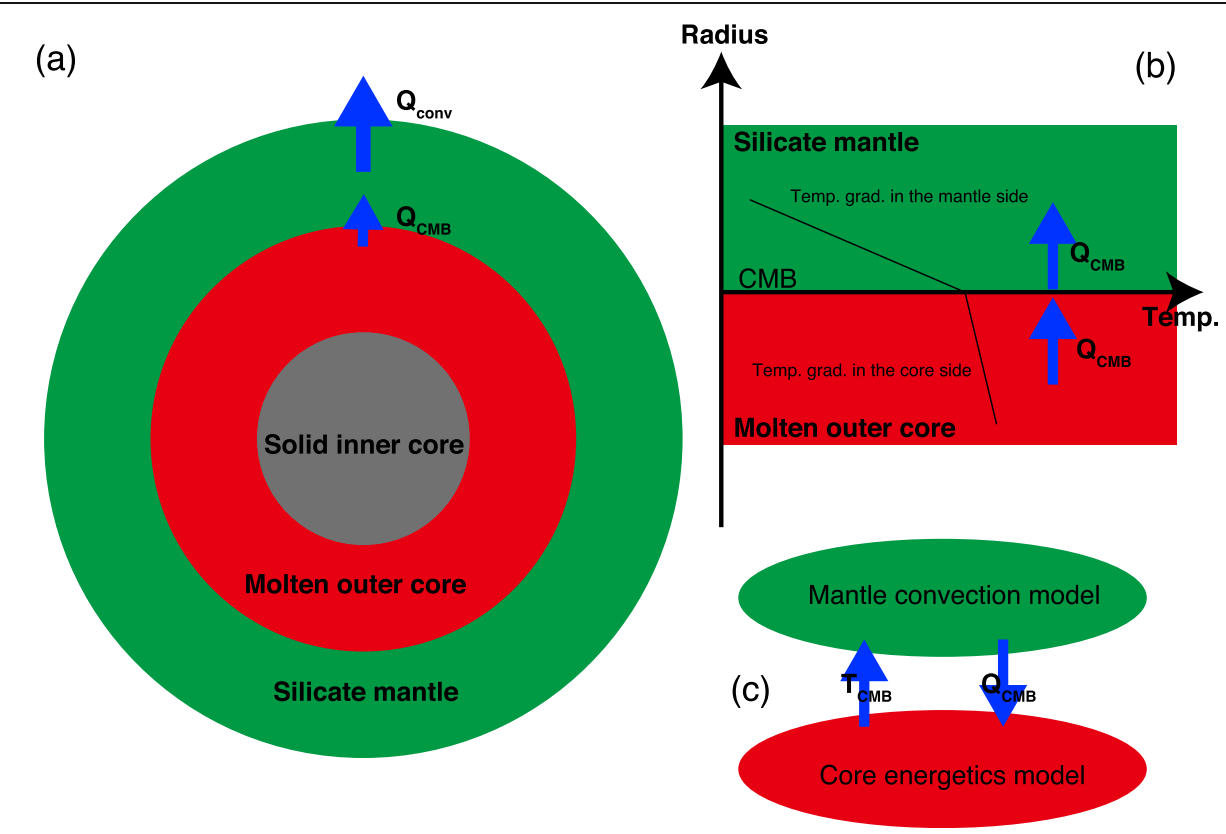

Fig. 2 a Schematic concept of the coupled core-mantle evolution model; b zoom-up of $\mathbf{a}$ at the core-mantle boundary. The heat flux across the core-mantle boundary should be continuous; hence, the heat flux just below the core-mantle boundary (core side) must be the same as the heat flux for just above the core-mantle boundary (mantle side). c A schematic illustration for the concept of the feedback between the mantle convection and core evolution models. This illustration provides the CMB heat flow computed from the mantle convection model to the core evolution model, and then, feedback to the CMB temperature for the bottom boundary condition of the mantle convection model 
(2018), the thermal energy balance of the Earth's core can be described as follows:

$$
Q_{\mathrm{CMB}}=Q_{C}+Q_{L}+E_{G}+Q_{R}
$$

where $Q_{\mathrm{CMB}}$ is the heat flow across the $\mathrm{CMB}$ given from the mantle convection model, $Q_{c}$ is the secular cooling caused by the convective hear transport, $Q_{L}$ is the latent heat release, $E_{G}$ is the gravitational energy release caused by the inner core growth, and $Q_{R}$ is the heat production caused by the radioactive elements in the core alloy. Partitioning of radioactive elements indicates that the heat production elements are likely to concentrate into the silicate mantle rather than the metallic core (Hirose et al. 2013; Watanabe et al. 2014). Therefore, the heat production effects are not considered here; the energy balance across the core is given as follows:

$$
Q_{\mathrm{CMB}}=Q_{C}+Q_{L}+E_{G}
$$

Since the secular cooling term can be given as follows:

$$
Q_{C}=-M_{c} c_{c} \frac{d T_{c}}{d t}
$$

the thermal energy balance can be simply arranged as follows:

$$
M_{c} c_{c} \frac{d T_{c}}{d t}=-Q_{\mathrm{CMB}}+Q_{L}+E_{G}
$$

where $T_{c}$ is the temperature at the inner core boundary, $M_{c}$ is the mass of the outer core, and $c_{c}$ is the heat capacity of the outer core. The detailed formulations of the latent heat release and gravitational release caused by the inner core growth are given in Labrosse (2015). Using this energy balance, it is possible to compute the growth rate of the inner core. To compute the temperature at the core-mantle boundary, which may provide feedback to the mantle convection, the structure of the core should be assumed as having an isentropic temperature profile with an entirely mixed condition. This is because the convection of the Earth's core is excessively vigorous, so the convection of the Earth's core may be turbulent (e.g., Schaeffer et al. 2017). The temperature at the core-mantle boundary is expressed by the temperature at the inner core boundary:

$$
T_{\mathrm{CMB}}=T_{c}\left(\frac{\rho_{c}(b)}{\rho_{c}(c)}\right)^{-\gamma}
$$

where $b$ and $c$ are the radii of the Earth's outer and inner core, respectively, and $\gamma$ is the Grüneisen parameter.

When the inner core starts growing, the compositional convection is valid because the light element of the Earth's core should be released to the molten part of the metallic core; this dynamic plays an important role in the additional driving force of the core convection (e.g., Takehiro and Sasaki 2018). For the compositional balance in the outer core, as described in Buffett and Seagle (2010) and Takehiro and Sasaki (2018), the chemical composition of the light elements in the Earth's core can be given as follows:

$$
M_{c} \frac{d X_{c}}{d t}=S_{\mathrm{ICB}}+S_{\mathrm{CMB}}
$$

where $X_{c}$ is the entirely mixed concentration of the light elements in the convective region of the Earth's outer core, and $S_{\mathrm{ICB}}$ is the chemical flux associated with the inner core growth because the light elements is released to the molten core with the inner core growing, which is given as follows:

$$
S_{\mathrm{ICB}}=4 \pi c^{2} \rho_{c}(c) X_{0} \frac{d c}{d t}
$$

$X_{0}$ is the initial concentration of the light elements, $d c / d t$ is the growth rate of the inner core computed from the thermal energy balance shown in Eq. (4), and $S_{\mathrm{CMB}}$ is the chemical flux across the core-mantle boundary as a result of the chemical reaction between the silicate mantle and metallic core as shown in Frost et al. (2010) and Gubbins and Davies (2013). Detailed formulations of the chemical flux associated with the inner core growth are shown in Takehiro and Sasaki (2018).

With the aforementioned thermal and chemical balances, there are two methods for assessing the magnetic field generation caused by the convective actions in the Earth's core, including computing the magnetic dissipation from the thermal energy balance and the scaling law of the strength of the magnetic field associated with the convective fluxes.

For the ohmic dissipation approach, the total energy dissipation is given from the thermal balance as shown in Eqs. (29) to (35) of Labrosse (2015):

$$
\Phi=T_{\Phi}\left[\eta_{c} Q_{C}+\eta_{L} Q_{L}+\frac{E_{G}}{T_{\mathrm{CMB}}}-S_{k}\right]
$$

where $T_{\Phi}$ is the dissipation temperature, $\eta_{c}$ and $\eta_{L}$ are the Carnot efficiencies caused by the convective cooling and latent heat release, respectively, caused by the inner core growth, and $S_{k}$ is the entropy sink caused by the isentropic temperature profile given as follows:

$$
S_{k}=\int_{V} k\left(\frac{1}{T_{a}(r)} \frac{d T_{a}(r)}{d r}\right)^{2} d V
$$

where $k$ is the thermal conductivity of the core alloy, and $T_{a}(r)$ is the isentropic temperature of the molten core. As the thermal conductivity is sufficiently high, the entropy sink becomes larger. Hence, with a high thermal conductivity, the entropy production caused by the core 
convection is reduced to suppress the magnetic field generation.

For the convective flux approach, the thermal and chemical convective fluxes are given as follows: the scaling relationship between the convective flux and magnetic field generation is provided in Olson and Christensen (2006) and Aubert et al. (2009). For the convective fluxes caused by the thermal and chemical convection of the Earth's core, as shown in Takehiro and Sasaki (2018), the radial entropy flux is given as follows:

$$
F_{S}(r)=\frac{Q_{\text {conv }}(r)-\mu(r) F_{c}(r)}{T_{a}(r)}
$$

where $Q_{\text {conv }}(r)=Q_{c}(r)+Q_{L}(r)+E_{G}(r)+Q_{S}(r)$, which is given as the total heat flow caused by the thermal convection, $\mu(r)$ is the chemical potential change caused by the inner core solidification, and $F_{c}(r)$ is the compositional convective flux given as follows:

$$
F_{c}(r)=S_{\mathrm{ICB}}+S_{\mathrm{CMB}}-X_{c}
$$

With these convective fluxes, the power generated by the buoyancy force of the core convection is given as follows:

$$
w_{b}(r)=g(r)\left(\frac{\alpha_{T} T_{c}(r)}{c_{p}} F_{S}(r)-\alpha_{c} F_{c}(r)\right)
$$

where $w_{b}(r)$ is the radial profile of the work performed by the convective buoyancy flux, and $\alpha_{T}$ and $\alpha_{c}$ are the thermal and chemical expansivity, respectively. The magnetic moment at the $\mathrm{CMB}$ can be computed with the scaling law derived from geodynamo simulations given as follows:

$$
M=4 \pi b^{3}\left(\frac{\rho_{c}(b)}{2 \mu_{0}}\right)^{\frac{1}{2}}\left(\frac{(b-c) w_{b}(b)}{4 \pi b^{2} \rho_{c}(b)}\right)^{\frac{1}{3}}
$$

where $\mu_{0}=4 \pi \times 10^{-7}(\mathrm{H} / \mathrm{m})$ is the magnetic permeability. This scaling formula is only valid when $w_{b}(r)>0$; otherwise, the magnetic moment should be zero.

Figure 3 shows the magnetic evolution computed for two approaches (using Eqs. (8) and (13)) with $13 \mathrm{TW}$ of the heat flow across the present-day CMB. Both approaches provide a consistent profile of the magnetic evolution indicating that there is a huge jump of the magnetic intensity or dissipation caused by the onset of the inner core growth. This jump also corresponds to the change of the dynamics of the Earth's core from purely thermal convection into thermal and chemical convection. The growth of the inner core is a major mechanism that can maintain the magnetic field at the present time. Hence, they are useful in determining the

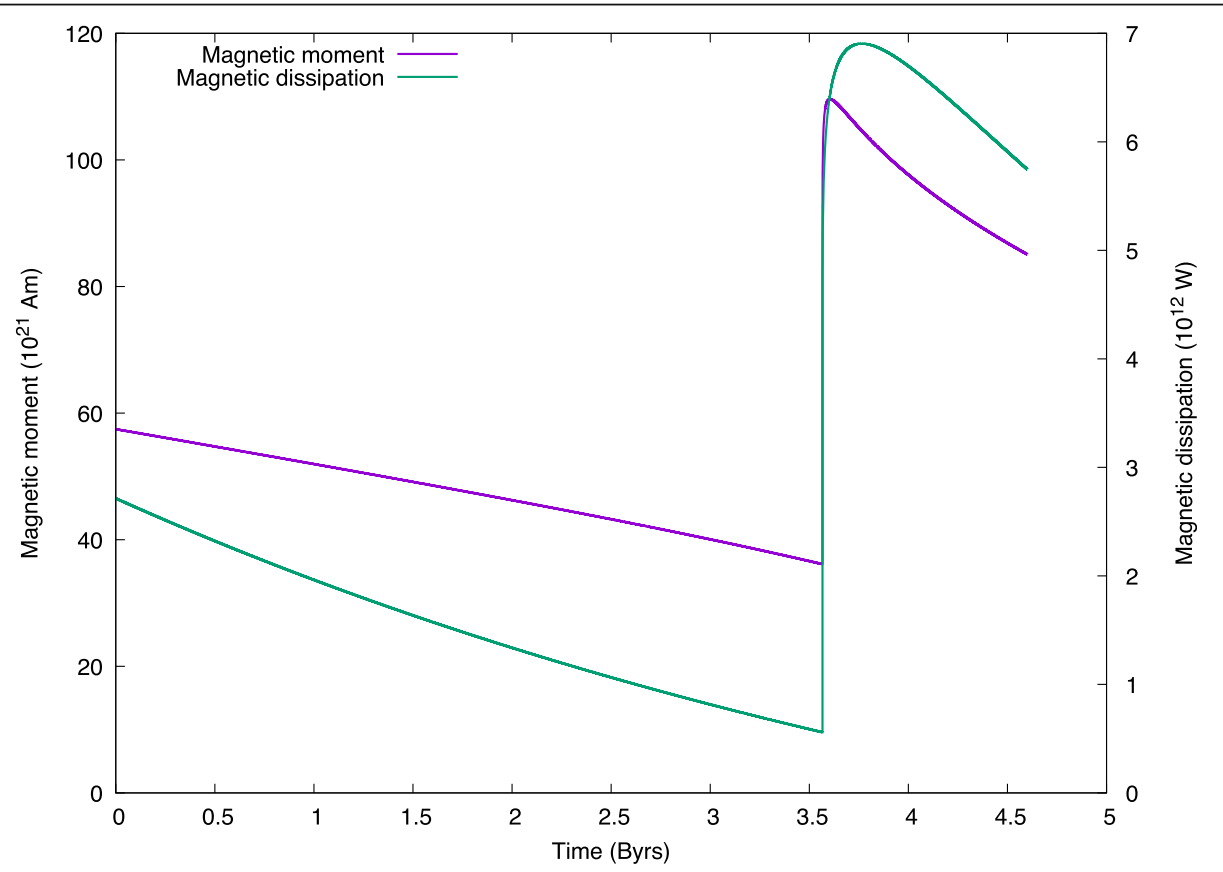

Fig. 3 Magnetic evolution profiles with 13 TW of the heat flow across the CMB at present. The heat flow across the CMB is assumed as: $Q_{C M B}$ $=Q_{\mathrm{CMB}, p} \exp \left(\frac{f\left(t_{a}-t\right)}{t_{0}}\right)$ where $Q_{\mathrm{CMB}, p}$ is the present-day heat flow across the $C M B, f=\ln \left(Q_{C M B}, o / Q_{C M B}, p\right) / t_{a,}, Q_{C M B, o}$ is the initial value of the heat flow across the CMB, which is $25 \mathrm{TW}$, and $t_{a}$ is the age of the Earth (4.6 billion years) 
Table 2 Typical parameters used in Fig. 3 taken mostly from Labrosse (2015)

\begin{tabular}{|c|c|c|}
\hline Notation & Parameter & Value \\
\hline$\rho_{0}$ & Density at the center & $12451 \mathrm{~kg} \mathrm{~m}^{-3}$ \\
\hline$L_{\rho}$ & Density scale height & 8039 \\
\hline$A_{\rho}$ & 4th order polynomial fitting constant of the density & 0.484 \\
\hline$b$ & Core radius & 3486 km \\
\hline c & Inner core radius & $1221 \mathrm{~km}$ at the present \\
\hline$k_{c 0}$ & Thermal conductivity at the center & $163 \mathrm{~W} / \mathrm{m} / \mathrm{K}$ or $125 \mathrm{~W} / \mathrm{m} / \mathrm{K}$ \\
\hline$A_{k}$ & Radial dependence of thermal conductivity & 2.39 \\
\hline y & Grüneisen parameter & 1.5 \\
\hline$\left(\frac{\partial T_{m}}{\partial P}\right)_{X}$ & Pressure derivative of melting temperature & $9 \times 10^{-9} \mathrm{~K} / \mathrm{Pa}$ \\
\hline$\left(\frac{\partial T_{m}}{\partial X}\right)_{P}$ & Compositional derivative of melting temperature & $-2.1 \times 10^{4} K^{-1}$ \\
\hline$x_{0}$ & Initial concentration of light elements of the Earth's core & $5.6 \%$ \\
\hline$\Delta x p_{l}$ & Density difference across the ICB & $580 \mathrm{~kg} \mathrm{~m}^{-3}$ \\
\hline$c_{p}$ & Heat capacity & $750 \mathrm{~J} \mathrm{~K}^{-1} \mathrm{~kg}^{-1}$ \\
\hline$T_{m 0}$ & Melting temperature at the center & $5300 \mathrm{~K}^{\mathrm{j}}$ \\
\hline
\end{tabular}

long-term magnetic evolution caused by the geodynamo actions in the Earth's core. The typical physical parameters used in Fig. 3 are listed in Table 2.

\subsection{Parameterized mantle convection: brief evolution scenario}

The parameterized convection approach for the heat budget across the whole mantle is used to compute the coupled core-mantle evolution (Stevenson et al. 1983; Driscoll and Bercovici 2014). In this approach, the energy balance of the mantle convection is given as follows:

$$
M_{m} c_{m} \frac{d T_{m}}{d t}=Q_{\mathrm{CMB}}+H_{m}-Q_{s}-Q_{m e l t}
$$

where $T_{m}$ is the mass averaged temperature in the silicate mantle, $M_{m}$ is the mass of the silicate mantle, $c_{m}$ is the heat capacity of the mantle, $H_{m}$ is the radioactive heat production in the silicate mantle, and $Q_{\text {melt }}$ is the heat extraction caused by the melt migration across the mantle. This approach is approximated for the heat transfer of the mantle convection using the scaling relationship between the heat flow and convective vigor, given as:

$$
Q \sim R a^{\beta}
$$

or

$$
Q \sim v^{-\beta} \Delta T^{1+\beta}
$$

where $R a$ is the Rayleigh number described for the ratio of the buoyancy force to the viscous resistance, $\Delta T$ is the temperature difference across the boundary, $v$ is the kinematic viscosity depending on temperature and pressure, and $\beta$ is the power law index derived from the scaling relationship. Regarding the power law index $\beta$, there are certain choices depending on the rheological properties of the silicate mantle and dynamics of the mantle. However, as investigated by Honda (1996), the value of this index is approximated as 0.3 , which is applicable to the most complicated setting of the mantle convection. Certain improvements have been made for the scaling law of heat transfer across the mantle, including the heat transfer associated with plate tectonics (e.g., Korenaga 2010) and the transport of partially molten material with the mantle convection (e.g., Fraeman and Korenaga 2010). Figure 4 shows an example of the core-mantle evolution computation in the parameterized mantle convection model, including the heat transfer associated with the partially molten material (Driscoll and Bercovici 2014). With this figure, the evolution of the Earth's mantle and core can be briefly found, which indicates $\sim 10 \mathrm{TW}$ of the CMB heat flow and $\sim 40 \mathrm{TW}$ of the surface heat flow. The age of the inner core is around 1.5 billion years. On the magnetic intensity profile, I checked two values of the thermal conductivity of the Earth's core $(125 \mathrm{~W} / \mathrm{m} / \mathrm{K}$ and $163 \mathrm{~W} / \mathrm{m} / \mathrm{K})$ because this property contains a huge uncertainty ranging from 16 to $220 \mathrm{~W} / \mathrm{m} / \mathrm{K}$ (Konôpková et al. 2016; Ohta et al. 2016). For $163 \mathrm{~W} / \mathrm{m} / \mathrm{K}$ taken from Gomi et al. (2013), the magnetic intensity is fallen into zero between 2.3 and 3.0 billion years from the initial state but, for 125 $\mathrm{W} / \mathrm{m} / \mathrm{K}$, the magnetic intensity indicates the positive value for 4.6 billion years. It is noted that the thermal evolution of the coupled core-mantle system is not changed with the value of the thermal conductivity of the Earth's core (Nakagawa and Tackley 2013). The typical physical values used in Fig. 4 are listed in Table 3. 

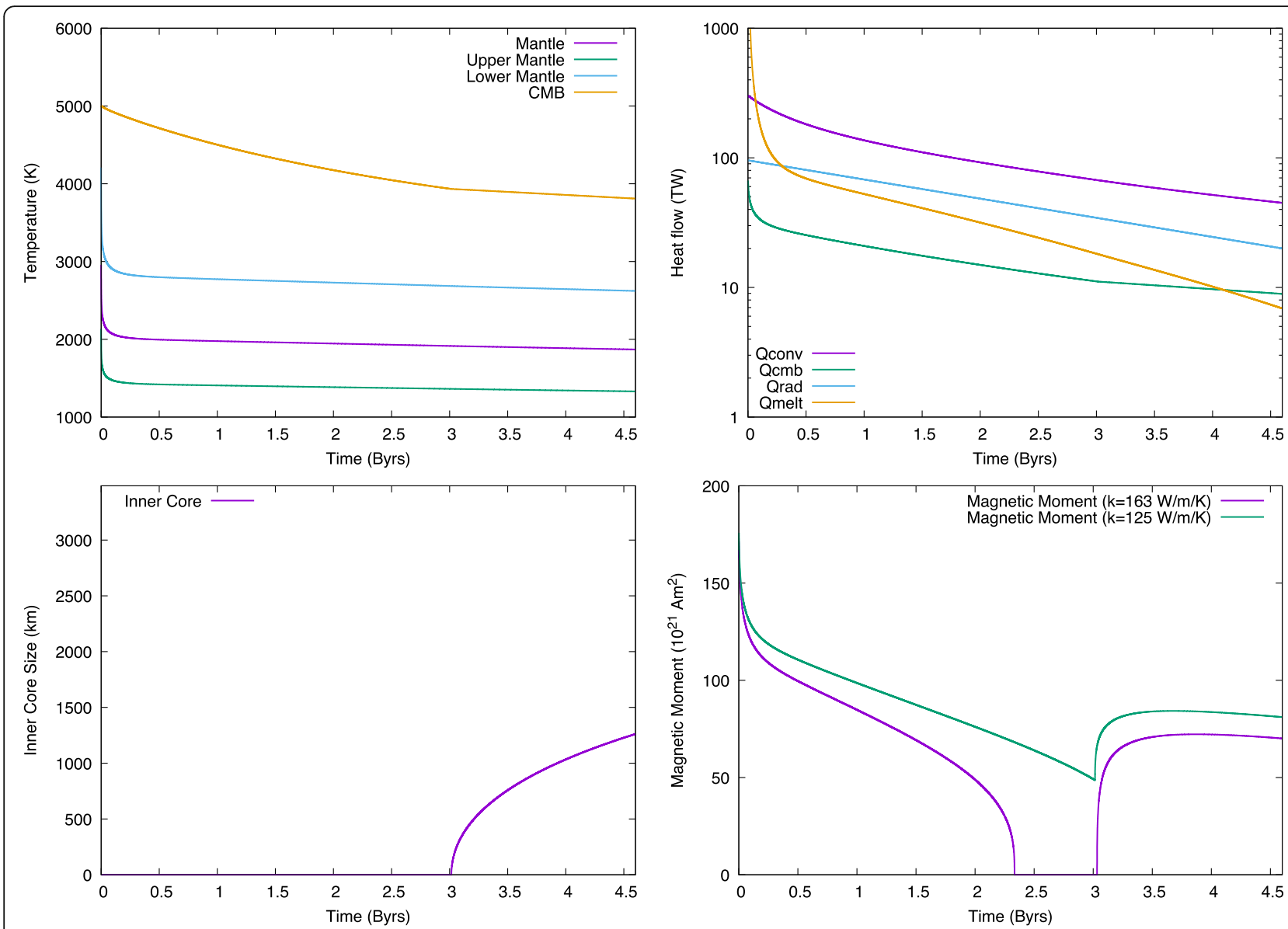

Fig. 4 Computed result of the coupled core-mantle evolution in a parameterized mantle convection with the mantle melting parameterization (Driscoll and Bercovici 2014). Top left: temperature (mass averaged mantle temperature, upper mantle, lower mantle, and core-mantle boundary); top right: heat flow (surface heat flow, heat flow across the CMB, heat producing elements in the mantle, and heat transport due to the partial melting); bottom left: inner core growth, which has $1.6 \mathrm{Ga}$ of the age of the inner core; bottom right: magnetic moments plotted for two values of the thermal conductivity at the center of the Earth's core. When the thermal conductivity is assumed as $163 \mathrm{~W} / \mathrm{m} / \mathrm{K}$ (Gomi et al. 2013), the magnetic field generation stops between 2.3 and 3.0 billion years. Conversely, the magnetic field may be continuously generated with $125 \mathrm{~W} / \mathrm{m} /$ $\mathrm{K}$ of thermal conductivity at the center of the Earth's core

4.3 Full mantle convection simulations: realistic modeling Full mantle convection simulations are used to compute the heat flow across the CMB instead of the parameterized convection. This is because the choice of the power law index may have a high uncertainty (Christensen 1985) and may not easily express the time variations of the horizontal length-scale, including the scaling relationship between heat transfer and convective vigor (e.g., Korenaga 2010). The first attempt made for the coupled core-mantle evolution based on the full mantle convection simulations was done with the effects of the origin of the thermochemical piles in the deep mantle (Nakagawa and Tackley 2004), where the heat flow buffering caused by the deep mantle heterogeneity would be required to explain the present-day size of the inner core. Including the rheological properties that allow for the generation of plate-like behavior and the effects of radioactive elements in the metallic core, a best-fit model that may explain both sizes of the inner core and the continuous magnetic field generation over 4 billion years was formulated (Nakagawa and Tackley 2005b; Nakagawa and Tackley 2010). Specifically, the initial temperature at the core-mantle boundary seems to be considerably higher than expected from the formation scenario of the Earth (Nakagawa and Tackley 2010). Additionally, the geologic constraints of the onset timing and mechanism of the plate tectonics (Moore and Webb 2013; Stern 2004) have been more recently formulated because the heat transfer of the plate tectonics may control the heat flow across the core-mantle boundary (Nakagawa and Tackley 2015). Figure 5 shows the results of the core-mantle evolution scenario with various strengths of the oceanic lithosphere as well as the mechanism of the onset of plate tectonics, which both demonstrate plume impacts to the viscous lid and heat pipe volcanism reproduced from Nakagawa and Tackley 
Table 3 Typical parameters used in Fig. 4, which are mostly taken from Driscoll and Bercovici (2014). For the core evolution, the typical parameters can be found in Table 2

\begin{tabular}{|c|c|c|}
\hline Symbol & Meaning & Value \\
\hline$\overline{\eta_{0}}$ & Reference viscosity & $7.0 \times 10^{11} \mathrm{Pas}$ \\
\hline$f_{\text {visc }}$ & Factor of depth change of viscosity & 10 \\
\hline$E$ & Activation energy & $300 \mathrm{~kJ} / \mathrm{mol}$ \\
\hline$\rho_{u m}$ & Density of the upper mantle & $3491 \mathrm{~kg} \mathrm{~m}^{-3}$ \\
\hline$\rho_{l m}$ & Density of the lower mantle & $5490 \mathrm{~kg} \mathrm{~m}^{-3}$ \\
\hline$M_{m}$ & Mass of the mantle & $4 \times 10^{24} \mathrm{~kg}$ \\
\hline$g$ & Gravity & $9.8 \mathrm{~m} \mathrm{~s}^{-2}$ \\
\hline$a_{u m}$ & Thermal expansivity of the upper mantle & $3 \times 10^{-5} \mathrm{~K}^{-1}$ \\
\hline$a_{l m}$ & Thermal expansivity of the lower mantle & $3 \times 10^{-5} \mathrm{~K}^{-1}$ \\
\hline$\kappa_{0}$ & Surface thermal diffusivity & $7 \times 10^{-7} \mathrm{~m}^{2} \mathrm{~s}^{-1}$ \\
\hline$c_{m}$ & Heat capacity & $1250 \mathrm{~J} \mathrm{~kg}^{-1} \mathrm{~K}^{-1}$ \\
\hline$L_{m}$ & Latent heat & $6.0 \times 10^{5} \mathrm{~J} \mathrm{~kg}^{-1}$ \\
\hline$H_{m}$ & Present-day internal heating rate & 20 TW \\
\hline$\varepsilon_{\text {erupt }}$ & Eruption rate & 1.0 \\
\hline$T_{\text {solo }}$ & Solidus temperature at the surface & $1244.0 \mathrm{~K}$ \\
\hline$Y_{a d, m}$ & Adiabatic gradient of the melt & $1 \mathrm{~K} / \mathrm{km}$ \\
\hline$\gamma_{z}$ & Solidus gradient with the depth & $3.9 \mathrm{~K} / \mathrm{km}$ \\
\hline$R$ & Gas constant & $8.314 \mathrm{~J} \mathrm{~K}^{-1} \mathrm{~mol}^{-1}$ \\
\hline
\end{tabular}

(2015). The strength of the oceanic lithosphere affects the heat transfer across the CMB, which indicates that cases with the long-term operating the surface plate motion can give the better core evolution with an aid of the basaltic piles. For the stronger plate $(0.2$ of the friction coefficient), the evolution profiles are similar to the case with the weaker plate ( 0.02 of the friction coefficient) because of no dense piles above the CMB.

For describing the more detailed effects on the heat pipe volcanism, Fig. 6 shows the zoom up of the diagnostic of the surface plate properties for both with and without melting effects up to 0.08 of the friction coefficient, and time variations of the viscosity field for 0.08 of the friction coefficient. A sudden increase of the magmatic heat transport corresponds to both plume impacts and heat pipe volcanism. This increasing the magmatic heat transport can find the same timing as the spike of the surface mobility (a ratio of surface velocity to the root-mean-square velocity of the mantle convection). This suggests that the both plume impacts and heat pipe volcanism can work for the driving mechanism of the onset of the plate subduction when the strength of the oceanic plate is sufficiently weak ( 0.04 of the friction coefficient; Fig. 6a, b). The heat pipe volcanism can aid the plate subduction when the oceanic lithosphere is fairly strong (see Fig. $5 \mathrm{c}, \mathrm{d}$ ) because the eclogite transition in the oceanic crust can give an additional downward buoyancy. The onset timing of the tectonic plate here indicates around $~ 60$ Myrs, which supports the onset timing of the plate subduction inferred by the geochemical analysis of the zircon (e.g., Hopkins et al. 2008). However, there are still huge uncertainties of the onset timing of the plate subduction (e.g., Korenaga 2013). A more detailed investigation will be needed in the future.

\section{Future prospects}

\subsection{Recent progress}

A recent travel time analysis of the seismic wave bouncing at the core-mantle boundary ( $\mathrm{SmKS}$ phase) indicates that the outermost outer core may have a slower speed than the reference seismic structure of the deep Earth (Tanaka 2007; Helffrich and Kaneshima 2010). The origin of this slow speed region in the outermost outer core, which is interpreted as the "stable" region (less convective zone), was noted by three theoretical models of the core evolution (Labrosse et al. 1997; Lister and Buffett 1998; Buffett and Seagle 2010). Labrosse et al. (1997) attempted to explain the stable region in the outermost outer core using an "adiabatic shell." Labrosse (2015) quoted the possibility of the stable region with the high value of the thermal conductivity in the heat budget of the Earth's outer core. Buffett and Seagle (2010) attempted to explain the origin of the stable region using the chemical coupling between the silicate mantle and metallic core by assuming that the oxygen would be a major light element of the Earth's core. However, both approaches could not explain the origin of the slow seismic wave speed at the outermost core, although the thickness of the region could be explained. Lister and Buffett (1998) attempted to include both the thermal and chemical origins of the stable region and noted that the thermal origin may be preferable. Nakagawa (2018) also attempted to decipher the origin of the stable region with the long-term evolution model of the Earth's core by allowing the formation of the stable region, but the region in the model seemed to be extremely stable and could not fully explain the seismic observations. Figure 7 shows an example of the coupled core-mantle evolution model, including the formation of the stable region in the outermost core. The stable region may stabilize the heat transfer across the core-mantle boundary, which indicates around $12 \mathrm{TW}$ of the CMB heat flow and $4000 \mathrm{~K}$ of the temperature at the CMB. Additionally, incorporating the stable region can get the better evolution of the Earth's core compared to the case without the stable region except for the magnetic evolution. However, further improvements are required to reveal the structure and evolution of the Earth's core in the coupled core-mantle evolution for explaining the early geodynamo action if the stable region would be more feasible for the structure of the Earth's core 

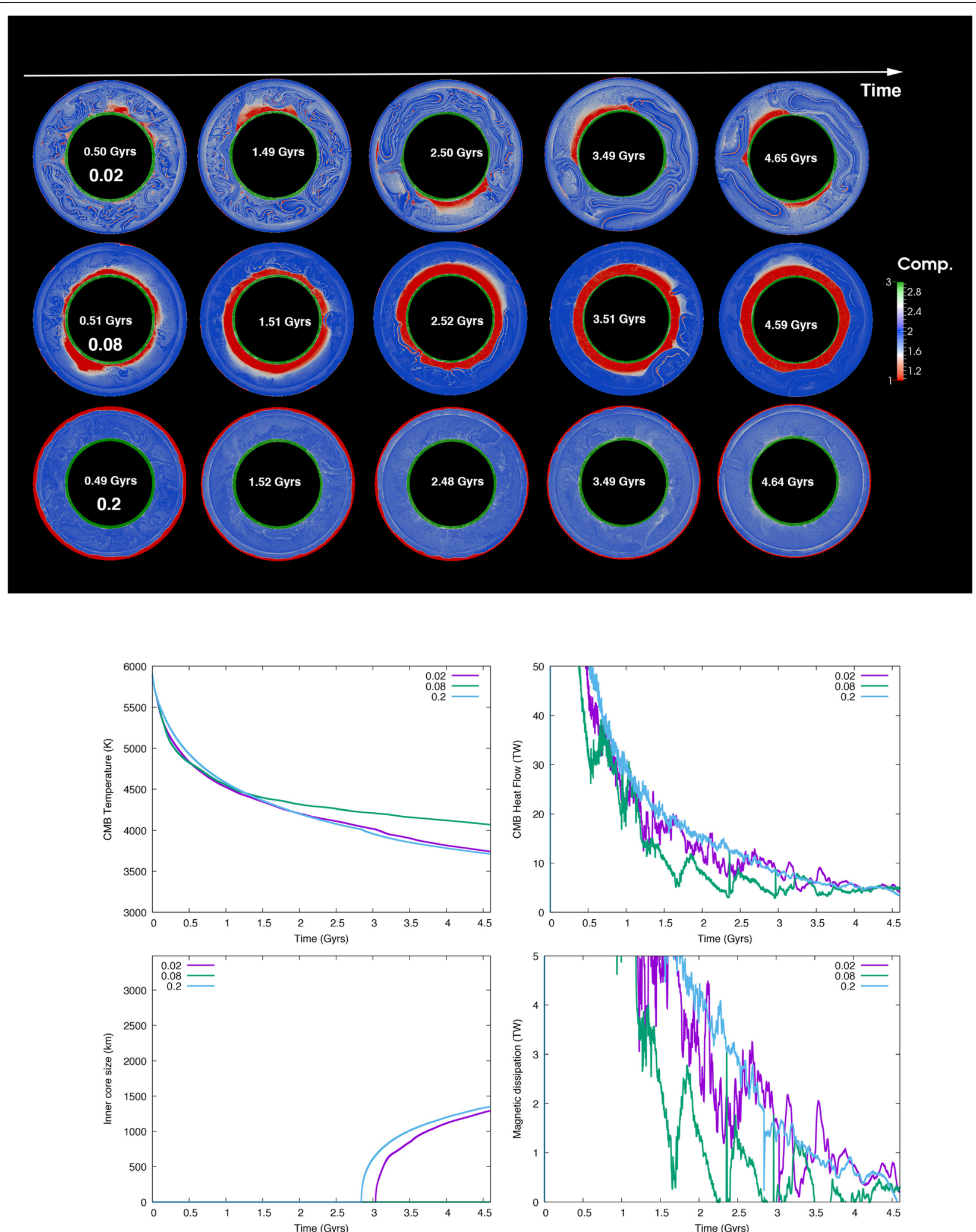

Fig. 5 Examples of the coupled core-mantle evolution varied with the strength of the oceanic lithosphere (i.e., different values of the friction coefficient of the brittle deformation of the oceanic lithosphere; see more details in Nakagawa and Tackley (2015)). Top: time variations of the chemical structure of the silicate mantle for selected values of the friction coefficient (blue: harzburgite, red: basaltic crust, and green: primordial material); bottom: diagnostics of the core evolution (temperature at CMB; heat flow across the CMB; inner core; magnetic dissipation) 


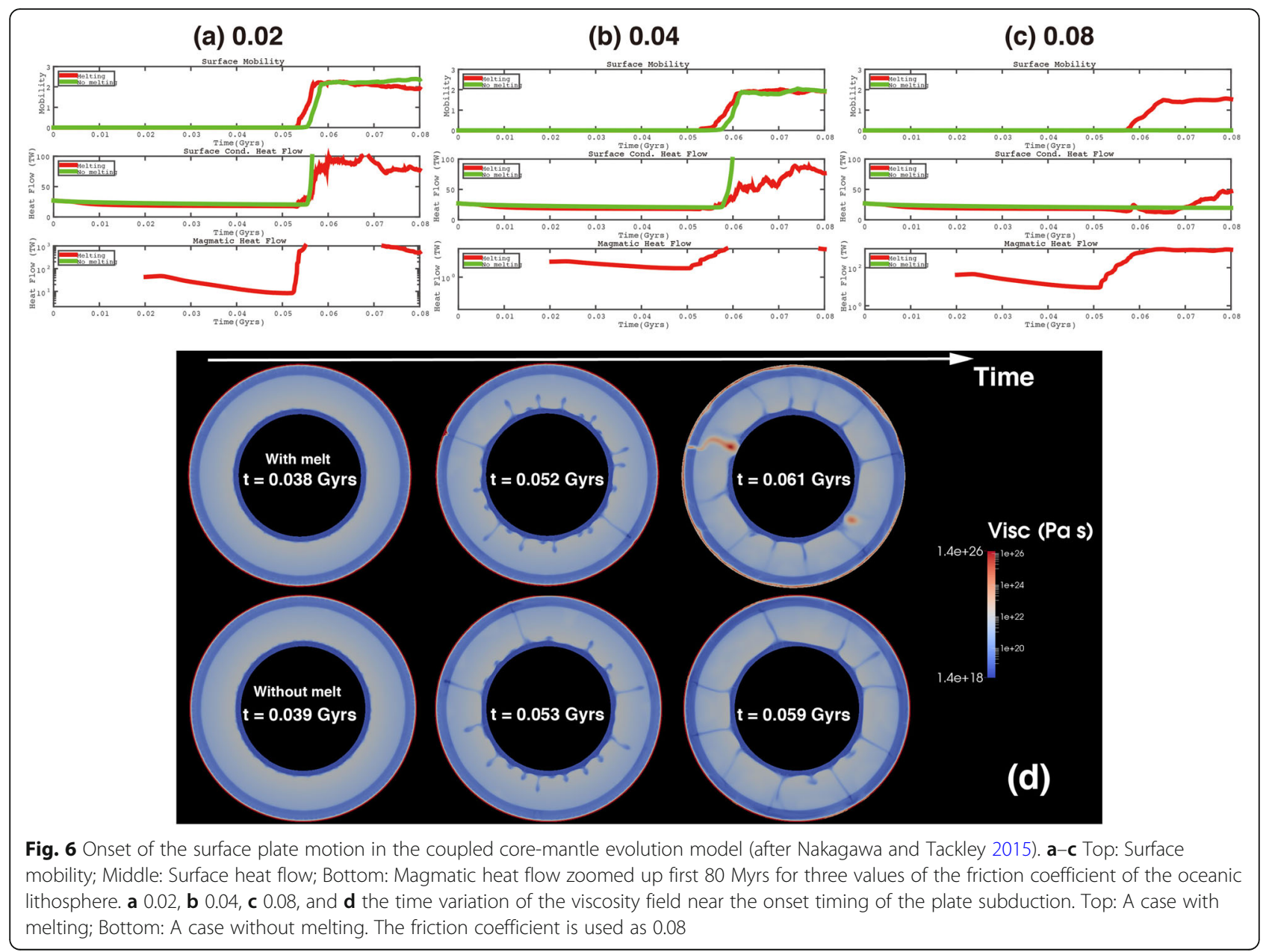

because the magnetic field generation is significantly weak with the stable region.

With geodynamo simulations that include a stable region, the intensity of the magnetic field is filtered due to the strong diffusion of the induced magnetic field through a stable region (Nakagawa 2015; Christensen 2018). Additionally, the stable region can work for the unstable dynamo actions because the magnetic field generation caused by core convection is suppressed by the stable region. Figure 8 shows an example of the magnetic field at the CMB for geodynamo simulations with/ without a stable region, which indicates a strong diffusion of the induced magnetic field in the stable region. Without the stratified region, the morphology of the magnetic field at the CMB indicates the dipoledominant feature. With the stable region, the amplitude of the magnetic field is much smaller, which is reduced to 0.01 of the cases without the stable region. The morphology of the magnetic field is dominated by the non-dipolar field. As discussed in Nakagawa (2015), this type of dynamo solution can have a bifurcation of the solution. Shown on the right side of Fig. 8 is the representative case for the weak field solution. Starting with the weak seed magnetic field, the dynamo solution is likely to be fallen into the weak field solution, whereas, with the strong seed magnetic field, the solution goes to the strong field solution but not stronger than the case without the stable region. Regarding the zonal flow structure, the equatorial jet can be developed for the case without the stable region but, with the stable region indicating the weak field solution, the columnar-type of flow is developed. However, it is noted that the dynamo actions with the stable region are still controversial if the stable region would be feasible or not because the contrary result of geodynamo simulations is provided that there would be less feasible for the stable region at the top of the Earth's core (Gastine et al. 2020).

Recent mineral physics experiments pointed out that silicate crystals may be found in the molten iron near the pressure at the core-mantle boundary (Hirose et al. 2017), and magnesium oxide may also be crystallized in the molten iron (Badro et al. 2016). This chemical process is an alternative convective process that occurs before the inner core starts growing, because the thermal 
(a)

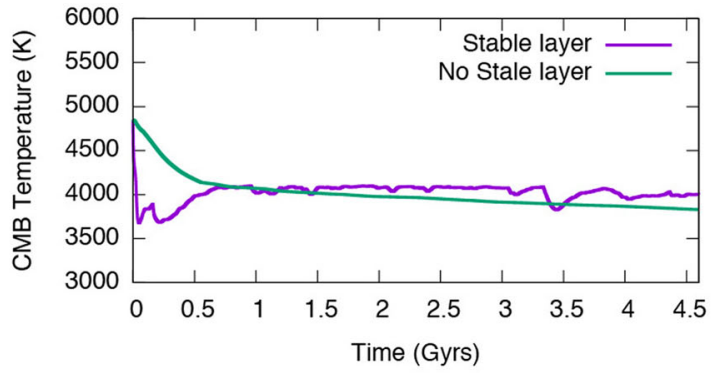

(c)

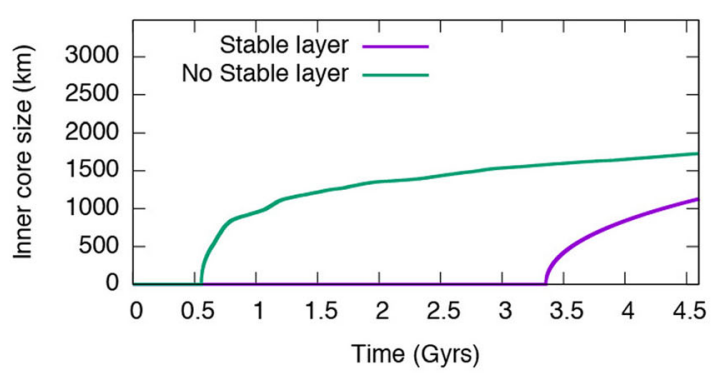

(b)

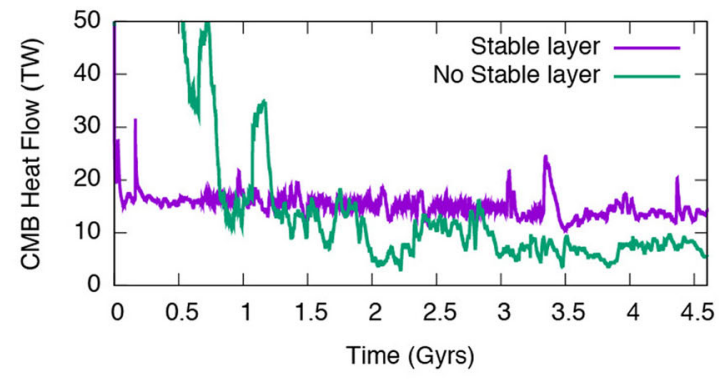

(d)

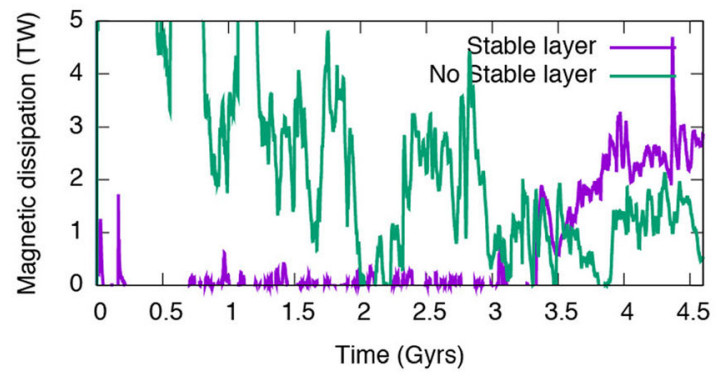

(e)

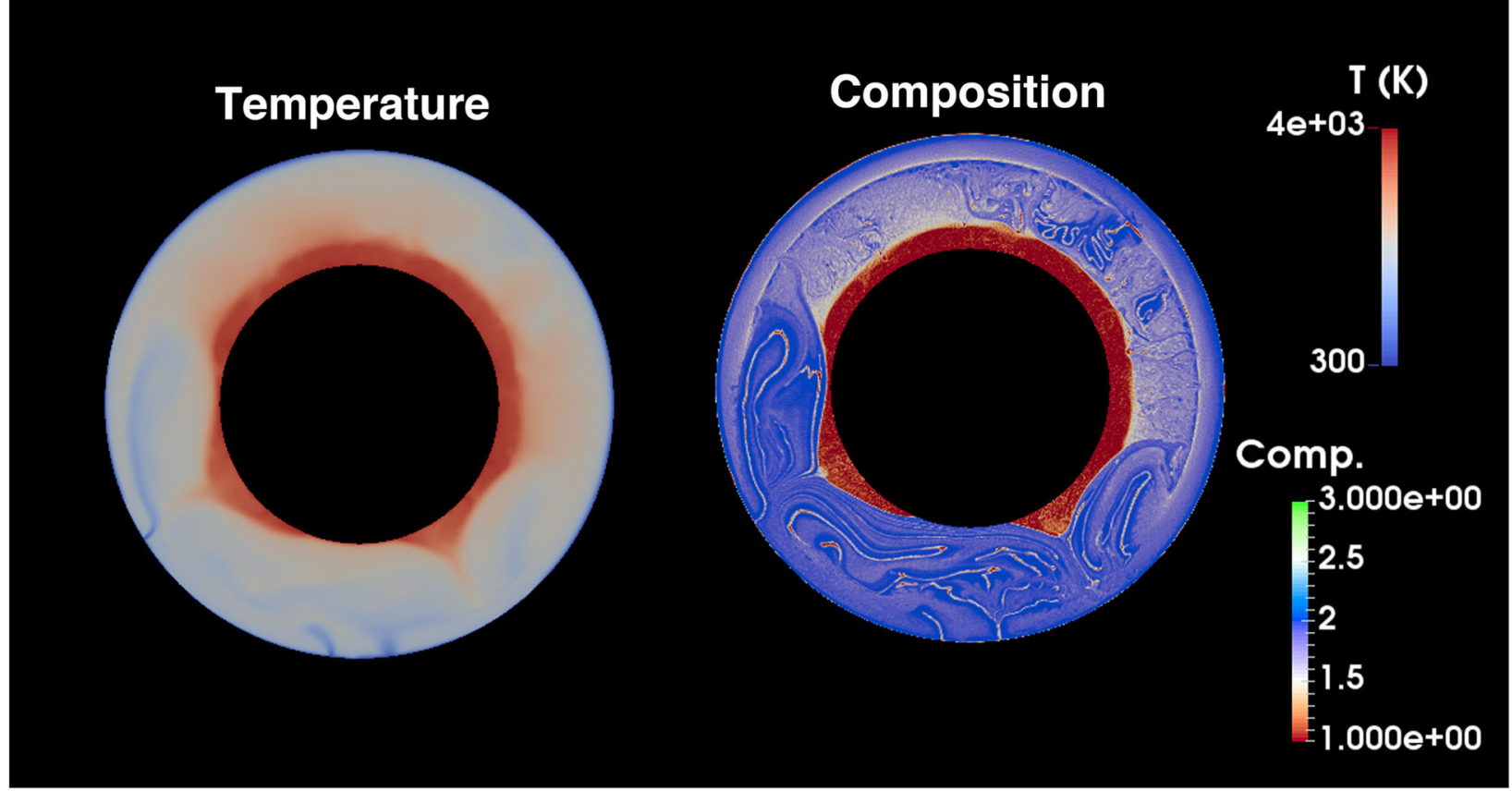

Fig. 7 Examples of the coupled core-mantle evolution in mantle convection simulations when inserting the formation of the stable region formulated by Nakagawa (2018). a Temperature at the CMB, $\mathbf{b}$ heat flow across the CMB, $\mathbf{c}$ inner core, $\mathbf{d}$ magnetic dissipation, and $\mathbf{e}$ thermal and chemical structure taken at $t=4.6$ Gyrs. For the chemical structure, blue indicates the depleted harzburgite and red indicates the enriched oceanic crust 


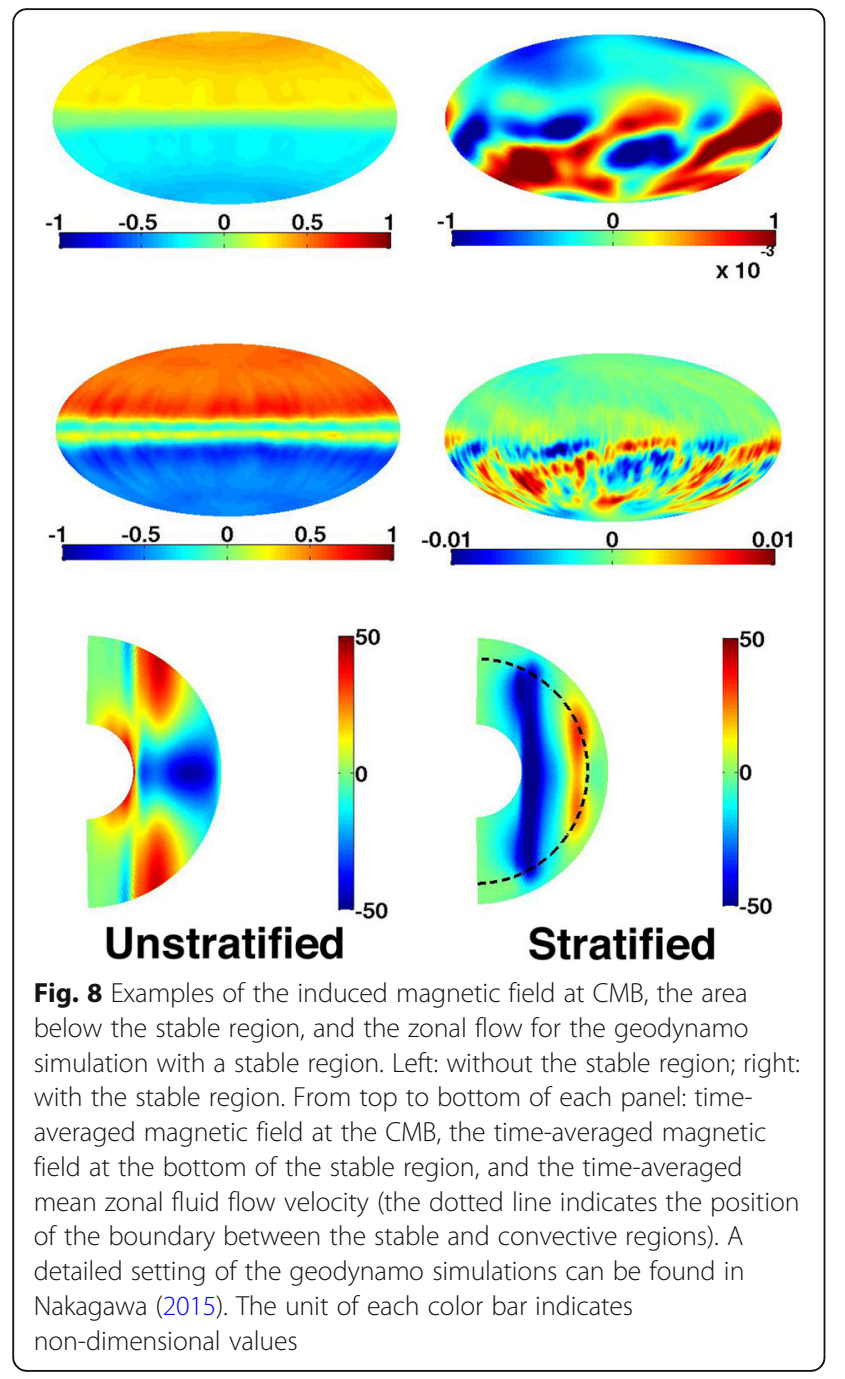

convection is strongly suppressed by the high thermal conductivity of the core alloy prior to the inner core growth. With theoretical estimates on how this crystallization contributes to the evolution and structure of the outermost core, both silicate and magnesium oxide may have less buoyancy than the surrounding metallic alloy; the exsolution of those materials may act as an additional buoyancy source for increasing the convective power of the Earth's core, especially for the geodynamo actions in the early Earth (O'Rourke and Stevenson 2016; Hirose et al. 2017). The crystalized material in the metallic alloy may also be assimilated with the silicate deep mantle with respect to the thermodynamics model (Helffrich et al. 2018). However, further investigation is needed for the contributions of the additional driving force caused by the material exsolution to the core convection and its thermal and chemical structure, and the onset timing of the geodynamo actions in the early Earth requires clarification.

\subsection{Shortcomings}

My review of the coupled core-mantle evolution discusses the proper determination of a consistent scenario with various observational constraints and interpretations. However, there are still considerable shortcomings in the field that need to be addressed in future research. These research gaps are listed as follows:

1. Evolution from the magma ocean: The solidification of the magma ocean is important in determining the initial condition of the mantle convection (e.g., Foley et al. 2014). The solidification of the magma ocean includes important questions towards determining the most accurate scenario of coremantle evolution, including the onset timing of the geodynamo actions and plate tectonics as well as planetary habitability. Additionally, the globally molten region known as the Basal Magma Ocean might be found in the deep interior (Labrosse et al. 2007), and it might have strongly affected the longterm evolution of the Earth's deep interior (e.g., Laneuville et al. 2018). The current modeling on the coupled core-mantle evolution has not included the effects of the solidification of the magma ocean in the early Earth. The physical and chemical processes for the solidification of the magmatic ocean should be included in future improvements.

2. Magnetic evolution: There is no completed fluid dynamic simulation model coupling the mantle and core because the time scales of the dynamics between the mantle and core are highly variant due to the extremely low viscosity of the Earth's outer core (e.g., Rutter et al. 2002). Strong computing power can simulate extreme modeling of dynamical coupling of the silicate and metallic core and thus improve interpretations of the magnetic evolution associated with core dynamics.

Additionally, the onset timing of the geodynamo actions is still controversial due to the energetics of the Earth's core with a high thermal conductivity of the core alloy; this is because the thermal convection is only the driving mechanism of the core convection before the onset timing of the inner core growth. To avoid the energy shortage caused by a high thermal conductivity, another energy source of the convective action that may have maintained the magnetic field generation in the early Earth has been proposed: compositional convection in the outermost core (O'Rourke and Stevenson 2016; Hirose et al. 2017). There have been several theoretical models based on the parameterized mantle convection for determining the long-term evolution scenario (e.g., O'Rourke et al. 2018), but such models have not been 
developed for the Earth's evolution. Further investigations of these energy sources are required so that the most accurate evolutionary scenario can be determined and paleomagnetic constraints for the long-term evolution can thus be improved. The other improvement is to look at the possibility of the magnetic field generation caused by the basal magma ocean (Ziegler and Stegman 2013) but not well investigated. This topic is worth working for testing such a hypothesis.

3. Plate tectonics: The timing of the onset of plate tectonics on the early Earth, which began just after the surface's magmatic ocean solidified, is not fully understood (e.g., Foley et al. 2014). Plate tectonics is the major heat engine used to maintain the heat flow across the core-mantle boundary and ensure that the convective action of the Earth's core can maintain the magnetic field generation. The current numerical modeling approach for the global-scale of the mantle convection that generated plate tectonics, i.e., the rheological properties of the silicate rocks, is still not realistic (Tackley 2000; Moresi and Solomatov 1998). More realistic rheological properties of the silicate rocks regarding the weakening mechanisms (dynamic friction, grain-size effects, and water weakening effects; Gerya et al. 2008; Bercovici and Ricard 2014; Karato and Barbot 2018) should be included in future investigations.

4. Planetary habitability: An ongoing research aim is to find an Earth-like rocky planet. However, the Earth is the only habitable rocky planet in the solar system. One important component of a habitable rocky planet is that its strong geomagnetic field can be maintained for over 4 billion years. Other essential components that have only been found on Earth are plate tectonics and mild climate with a waterbased ocean. Nakagawa and Iwamori (2019) indicated the long-term evolution of the magnetic field, plate tectonics, and water ocean in a coupled coremantle evolution model in hydrous mantle convection simulations. However, further investigations are required; these should include the atmosphereocean evolution for a long-term climate on the planetary surface (Foley and Driscoll 2016). Such a study would comprise a major advancement in determining the best-fit evolution scenario on for plate tectonics, the geodynamo, and climate simultaneously.

\section{Summary}

This study provides a comprehensive review of the Earth's coupled core-mantle evolution. The review includes important constraints arising from paleomagnetism and geomagnetism, interpretations from seismology and mineral physics measurements on the structure of the deep mantle and outermost outer core, and the current status of longterm evolution modeling of the coupled core-mantle evolution used in theoretical/numerical modeling of the mantle convection. The main points of this review are as follows: (1) The heat flow across the CMB plays a key role in the coupled core-mantle evolution over 4 billion years in terms of the amplitude and spatial pattern; (2) More investigations on the origin of the deep mantle heterogeneity are needed for verifying the heat flow across the CMB; and (3) The current accomplishments of the coupled core-mantle evolution model are still difficult to find the consistent scenario of the Earth's evolution because the initial condition is too approximated to provide the better evolution scenario.

Since the time scale of the Earth's plate tectonics and mantle convection is important for understanding the long-term evolution of the core and mantle, the determination of detailed dynamics concerning mantle convection is required for identifying the constraints of geomagnetism and paleomagnetism. Although the initial condition of the mantle convection is not entirely analogous for its present-day structure and dynamics in the deep mantle (e.g., Nakagawa and Tackley 2012), the dynamics concerning the early Earth, i.e., the initiation of plate tectonics and geodynamo actions, should be incorporated in long-term evolution studies; this approach can provide a systematic understanding of the Earth's evolution. Finally, more effort should be applied in various disciplines so that planetary habitability can be determined in terms of the structure, dynamics, and evolution of the Earth's deep interior.

\section{Abbreviations}

CMB: Core-mantle boundary; LLSVPs: Large Low Shear Velocity Provinces

\section{Acknowledgements}

I thank Paul Tackley and Bruce Buffett for their long-term support of my research activities and Slava Solomatov, Shin-ichi Takehiro, Masao Nakada, Yozo Hamano, and Takesi Yukutake for giving me inspirations for the long-term research activities on the core-mantle evolution. I also thank Toru Inoue and Tomoeki Nakakuki for providing the research environment in which this review was written in Hiroshima University. I appreciate Tomo Katsura and Eiji Ohtani for giving me this opportunity through a Nishida Prize nomination. This review was financially supported by the JSPS-MEXT grant-in-aid for the innovative research area of "Core-Mantle Co-evolution" (Grant number: 15H05834). I also thank Peter van Keken and anonymous reviewer for the constructive comments that are greatly improved for the original manuscript.

Author's contributions

This manuscript is written by the single author (TN). The author read and approved the final manuscript.

\section{Funding}

This review was financially supported by the JSPS-MEXT grant-in-aid for the innovative research area of "Core-Mantle Co-evolution" (Grant number: 15H05834).

Availability of data and materials

All simulation data in all figures is available upon request to the author. 


\section{Competing interests}

The author declares that they have no competing interests.

\section{Received: 20 March 2020 Accepted: 9 September 2020} Published online: 06 October 2020

\section{References}

Amit H., Choblet G. (2012). Mantle-driven geodynamo features - effects of compositional and narrow D" anomalies. Phys Earth Planet Inter 190-191: 3443

Aubert J, Labrosse S, Poitou C (2009) Modeling the paleo-evolution of the geodynamo. Geophys J Int 179:1414-1428

Aubert J, Finley CC, Fournier A (2013) Bottom-up control of geomagnetic secular variation by the Earth's inner core Nature 502: 219-223

Badro J, Siebert J, Nimmo F (2016) An early geodynamo driven by exsolution of mantle components from Earth's core. Nature 536:326-328

Bercovici D, Ricard Y (2014) Plate tectonics damage, and inheritance. Nature 508: $513-516$

Biggin A, Steinberger B, Aubert J, Suttie N, Holme R, Torsvik TH, van der Meer DG, van Hinsbergen DJJ (2012) Possible links between long-term geomagnetic variations and whole-mantle convection processes. Nat Geosci 5:526-533

Biggin A, Piispa E, Pesonen L, Holme R, Paterson G, Veikkolainen T, Tause L (2015) Palaeomagnetic field intensity variations suggest mesoproterozioc inner-core nucleation. Nature 526:245-248

Bloxham J, Gubbins D, Jackson A (1989) Geomagnetic secular variation. Philos Trans R Soc London A 329:415-502

Buffett BA, Seagle CT (2010) Stratification of the top of the core due to chemical interactions with the mantle. J Geophys Res 115:B04407. https://doi.org/10. 1029/2009JB008376

Buffett BA, Huppert HE, Lister JR, Woods AW (1996) On the thermal evolution of the Earth's core. J Geophys Res 101:7989-8006. https://doi.org/10.1029/ 95JB03539

Bullard EC, Freedman C, Gellman H, Nixon J (1950) The westward drift of the Earth's magnetic field. Philos Trans R Soc 850:67-92

Burdick S, Waszek L, Lekic V (2019) Seismic tomography of the uppermost inner core. Earth Planet Sci Lett 528:115789. https://doi.org/10.1016/j.epsl.2019. 115789

Christensen UR (1985) Thermal evolution models for the Earth. J Geophys Res 90: 2995-3007

Christensen U $(2018,215)$ Geodynamo models with a stable layer and heterogeneous heat flow at the top of the core. Geophys J Int:1338-135

Courtillot V, Besse J (1987) Magnetic field reversals, polar wander, and coremantle coupling. Science 237:1140-1147

Courtillot V, Olson P (2007) Mantle plumes link magnetic superchrons to phanerozoic mass depletion events. Earth Planet Sci Lett 260:495-504

Davies CJ (2015) Cooling history of Earth's core with high thermal conductivity. Phys Earth Planet Inter 247:67-79

Deschamps F, Kaminski E, Tackley PJ (2011) A deep mantle origin for the primitive signature of ocean island basalt. Nat Geosci 4:879-882. https://doi. org/10.1038/ngeo1295

Deschamps F, Rogister Y, Tackley PJ (2018) Constrains on core-mantle boundary topography from models of thermal and thermochemical convection. Geophys J Int 212:164-188. https://doi.org/10.1093/gji/ggx402

Deuss A (2014) Heterogeneity and anisotropy of Earth's inner core. Annu Rev Earth Planet Sci 42:103-126. https://doi.org/10.1146/annurev-earth-060313054658

Driscoll P, Bercovici D (2014) On the thermal and magnetic histories of Earth and Venus: influence of melting, radioactivity, and conductivity. Phys Earth Planet Inter 236:36-51

Ernst RE, Youbi N (2017) How large igneous provinces affect global climate sometimes cause mass extinctions, and represent natural markers in the geologic record. Palaeogeoph Palaeoclim Palaeoecol 478:30-52

Foley BJ, Driscoll DE (2016) Whole planet coupling between climate, mantle, and core: implications for rocky planet evolution. Geochem Geophys Geosyst 17: 1885-1914. https://doi.org/10.1002/2015GC006210

Foley BJ, Bercovici D, Elkins-Tanton LT (2014) Initiation of plate tectonics from post-magma ocean thermochemical convection. J Geophys Res 119:85388561. https://doi.org/10.1002/2014JB011121

Fraeman AA, Korenaga J (2010) The influence of mantle melting on the evolution of Mars Icaurs 210: 43-57
Frost DJ, Asahara Y, Rubie DC, Miyajima N, Dubeonvinsky LS, Holzapfel C, Ohtani E, Miyahara M, Sakai T (2010) Partitioning of oxygen between the Earth's mantle and core. J Geophys Res 115:B02202. https://doi.org/10.1029/ 2009JB006302

Gastine T, Aubert J, Fournier A (2020) Dynamo-based limit to the extent of a stable layer atop Earth's core. Geophys J Int 222:1433-1448

Gerya T, Connolly JAD, Yuen DA (2008) Why terrestrial subduction one-sided? Geology 36:43-46. https://doi.org/10.1130/G24060A.1

Glatzmaier GA, Coe RS, Hongre L, Roberts PH (1999) The role of the Earth's mantle controlling the frequency of geomagnetic reversals. Nature 401:885890

Gomi H, Ohta K, Hirose K, Labrosse S, Caracas R, Verstraete MJ, Hernlund JW (2013) The high conductivity of iron and thermal evolution of the Earth's core. Phys Earth Planet Inter 224:88-103

Gubbins D, Davies CJ (2013) The stratified layer at the core-mantle boundary caused by baro-diffusion of oxygen, Sulphur and silicon. Phys Earth Planet Inter 215:21-28

Gubbins D, Sreenivasan B, Mound J, Rost S (2011) Melting of the Earth's inner core. Nature 473:361-363

Helffrich G, Kaneshima S (2010) Outer-core compositional stratification from observed core wave speed profiles. Nature 468:807-809

Helffrich G, Ballmer M, Hirose K (2018) Core-exsolved SiO2 dispersal in the Earth's mantle. J Geophys Res 123:1161-1164. https://doi.org/10.1002/2017JB014865

Hirose K, Labrosse S, Hernlund J (2013) Compositional state of Earth's core. Annu Rev Earth Planet Sci 41:657-691

Hirose K, Morard G, Sinmyo R, Umemoto K, Hernlung J, Helffrich G, Labrosse S (2017) Crystallization of silicon dioxide and compositional evolution of the Earth's core. Nature 543:99-102. https://doi.org/10.1038/nature21367

Honda S (1996) Local Rayleigh and Nusselt numbers for cartesian convection with temperature-dependent viscosity. Geophys Res Lett 23:2445-2448

Hopkins M, Harrison TM, Manning CE (2008) Low heat flow inferred from > 4 Gyr zircons suggests Hadean plate boundary interactions. Nature 456:493-496. https://doi.org/10.1038/nature07465

Ishii M, Tromp J (1999) Normal-mode and free-air gravity constraints on lateral variations in velocity and density of Earth's mantle. Science 285:1231-1236

Jaupart C, Labrosse S, Marechal JC (2007) Temperatures, heat and energy in the mantle of the Earth. Treatise on Geophysics 7:99-164

Jones T D, Maguire R R, van Keken P E, Ritsema J, Koelemeijer P (2020) Subducted oceanic crust as the origin of seismically slow lower-mantle structures, Prog Earth and Planet Sci, 7: doi: https://doi.org/10.1186/s40645020-00327-1144.

Karato S, Barbot S (2018) Dynamics of fault motion and the origin of constraining tectonic style between. Earth and Venus, Sci Rep 8:11884. https://doi.org/10. 1038/s41598-018-30174-6

Koelemeijer P, Schuberth BSA, Davies DR, Deuss A, Ritsema J (2018) Constraints the presence of post-perovskite in Earth's lowermost mantle from tomographic-geodynamic model comparisons. Earth Planet Sci Lett 292:226238. https://doi.org/10.1016/j.epsl.2018.04.056

Konôpková Z, McWilliams RS, Gomez-Perez N, Goncharov AF (2016) Direct measurement of thermal conductivity in solid iron at planetary core conditions. Nature 534:99-101. https://doi.org/10.1038/nature18009

Korenaga J (2010) Scaling of plate tectonic convection with pseudoplastic rheology. J Geophys Res 115:B11405. https://doi.org/10.1029/2010JB007670

Korenaga J (2013) Initiation and evolution of plate tectonics on Earth: theories and observations. Annu Rev Earth Planet Sci 41(117-151):2013

Labrosse S (2015) Thermal evolution of the core with a high thermal conductivity. Phys Earth Planet Inter 247(36-55):2015

Labrosse S, Poirier J-P, Le Mouel J-L (1997) On cooling of the Earth's core. Phys Earth Planet Inter 99:1-17

Labrosse S, Poirier J-P, Le Mouel J-L (2001) The age of the inner core. Earth Planet Sci Lett 190:111-123

Labrosse S, Hernlund JW, Coltice N (2007) A crystallizing dense magma ocean at the base of the Earth's mantle. Nature 450:866-869. https://doi.org/10.1038/ nature06335

Laneuville M, Hernlund J, Labrosse S, Guttenbert N (2018) Crystallization of a compositionally stratified basal magma ocean. Phys Earth Planet Inter 276: 86-92. https://doi.org/10.1016/j.pepi.2017.07.007

Larson RL, Olson P (1991) Mantle plumes control magnetic reversal frequency. Earth Planet Sci Lett 107:437-447

Lay T, Hernlund J, Buffett BA (2008) Core-mantle boundary heat flow. Nat Geosci $1: 25-32$ 
Lister JR, Buffett BA (1995) The strength and efficiency of thermal and compositional convection in the geodynamo. Phys Earth Planet Inter 91:17-30

Lister JR, Buffett BA (1998) Stratification of the outer core at the core-mantle boundary. Phys Earth Planet Inter 105:5-19

Moore WB, Webb AAG (2013) Heat-pipe. Earth Nature 501:501-505. https://doi. org/10.1038/nature12473

Moresi L, Solomatov V (1998) Mantle convection with a brittle lithosphere: thoughts on the global tectonic styles of the Earth and Venus. Geophys J Int 133:669-682

Nakagawa T (2015) An implication for the origin of stratification below the coremantle boundary region in numerical dynamo simulations in a rotating spherical shell. Phys Earth Planet Inter 247:94-104. https://doi.org/10.1016/j. pepi.2015.02.007

Nakagawa T (2018) On thermo-chemical origin of stratified region at the top of Earth's core. Phys Earth Planet Inter 276:172-181. https://doi.org/10.1016/j. pepi.2017.05.011

Nakagawa T, Iwamori H (2019) On a core-mantle evolution in hydrous mantle convection simulations: implications for hydrogen cycle in the deep. Earth CR Geoscience 251:197-208

Nakagawa T, Tackley PJ (2004) Effects of thermo-chemical mantle convection on the thermal evolution of the Earth's core. Earth Planet Sci Lett 220:107-119

Nakagawa T, Tackley PJ (2005a) The interaction between the post-perovskite phase change and a thermo-chemical boundary layer near the core-mantle boundary. Earth Planet Sci Lett 238:204-216

Nakagawa T, Tackley PJ (2005b) Deep mantle heat flow and thermal evolution of the Earth's core in thermo-chemical multiphase models of mantle convection. Geochem Geophys Geosyst 6:Q08003. https://doi.org/10.1029/ 2005GC000967

Nakagawa T, Tackley PJ (2008) Lateral variations in CMB heat flux and deep mantle seismic velocity caused by a thermal-chemical-phase boundary layer in 3D spherical convection. Earth Planet Sci Lett 271:348-358

Nakagawa T, Tackley PJ (2010) Influence of initial CMB temperature and other parameters on the thermal evolution of Earth's core resulting from thermochemical spherical mantle convection. Geochem Geophys Geosyst 11: Q06001. https://doi.org/10.1029/2010GC003031

Nakagawa T, Tackley PJ (2012) Influence of magmatism on mantle cooling surface heat flow and Urey ratio. Earth Planet Sci Lett 329-330:1-10. https:// doi.org/10.1016/j.epsl.2012.02.011

Nakagawa T, Tackley PJ (2013) Implications of high core thermal conductivity on Earth's coupled mantle and core evolution. Geophys Res Lett 40. https://doi. org/10.1002/grl.50574

Nakagawa T, Tackley PJ (2015) Influence of plate tectonic mode on the coupled thermochemical evolution of Earth's mantle and core. Geochem Geophys Geosyst 16:3400-3413. https://doi.org/10.1002/2015GC005996

Nakagawa T, Tackley PJ, Deschamps F, Connolly JAD (2010) The influence of MORB and Harzburgite composition on thermo-chemical mantle convection in a 3-D spherical shell with self-consistently calculated mineral physics. Earth Planet Sci Lett 296:403-412

O'Rourke JG, Stevenson DJ (2016) Powering Earth's dynamo with magnesium precipitation from the core. Nature 529:387-389

O'Rourke J, Gillmann C, Tackley PJ (2018) Prospects for an ancient dynamo and modern crustal remnant magnetism on Venus. Earth Planet Sci Lett 502:4656. https://doi.org/10.1016/j.epsl.2018.08.055

Ohta K, Kuwayama Y, Hirose K, Shimizu K, Ohishi Y (2016) Experimental determination of the electrical resistivity of iron at Earth's core conditions. Nature 534:95-98

Olson P (2016) Mantle control of the geodynamo: consequences of top-down regulation. Geochem Geophys Geosyst 17:1935-1956. https://doi.org/10. 1002/2016/GC006334

Olson P, Christensen UR (2002) The time-averaged magnetic field in numerical dynamos with non-uniform boundary heat flow. Geophys J Int 151:809-823

Olson P, Christensen UR (2006) Dipole moment scaling from convection-driven planetary dynamos. Earth Planet Sci Lett 250:561-571

Olson P, Deguen R, Hinnov LA, Zhong S (2013) Controls on geomagnetic reversals and core evolution by mantle convection in the Phanerozoic. Phys Earth Planet Inter 214:87-103

Olson P, Deguen R, Rudolph ML, Zhong S (2015) Core evolution driven by mantle global circulation Phys Earth Planet Intert 243: 44-55

Pejic T, Tkalčić H, Sambridge M, Cormier VF, Benavente R (2017) Attenuation tomography of the upper inner core. J Geophys Res 112:3008-3032. https:// doi.org/10.1002/2016JB013692
Ritsema J, McNamara AK, Bull AL (2007) Tomographic filtering of geodynamic models: implications for model interpretation and large-scale mantle structure. J Geophys Res 112:B01303. https://doi.org/10.1029/2006JB004566

Ritsema J, Deuss A, van Heijst H-J, Woodhouse JH (2011) S40RTS: a degree-40 shear-velocity model for the mantle from new Rayleigh wave dispersion, tele-seismic traveltime and normal-mode splitting function measurements. Geophys J Int 184:1223-1236

Rutter MD, Secco RA, Uchida T, Liu H, Wang Y, Rivers ML, Sutton SR (2002) Towards evaluating the viscosity of the Earth's outer core: an experimental high pressure study of Fe-S (8.5 wt.\% S). Geophys Res Lett 29:1217. https:// doi.org/10.1029/2001GL014392

Schaeffer N, Jault D, Nataf H-C, Fournier A (2017) Turbulent geodynamo simulations: a leap towards Earth's core. Geophys J Int 211:1-29. https://doi. org/10.1093/gji/ggx265

Smirnov AV, Tarduno JA, Kulakov EV, McEnroe SA, Bono RK (2016) Paleointensity, core thermal conductivity and the unknown age of the inner core. Geophys J Int 205:1190-1195. https://doi.org/10.1093/gji/ggw080

Stern RJ (2004) Subduction initiation: spontaneous and induced. Earth Planet Sci Lett 226:275-292

Stevenson D, Spohn T, Schubert G (1983) Magnetism and thermal evolution of the terrestrial planets. Icarus 54:466-489

Tackley PJ (2002) Strong heterogeneity caused by deep mantle layering Geochem Geophys Geosyst, 3, doi: https://doi.org/10.1029/2001GC000167

Tackley P (2000) Self-consistent generation of tectonic plates in time-dependent, three-dimensional mantle convection simulations: 1. Pseudoplastic yielding. Geochem Geophys Geosyst 1:1021. https://doi.org/10.1029/2000GC000036

Takehiro S, Sasaki Y (2018) On destruction of a thermally stable layer by compositional convection in the Earth's outer core. Front Earth Sci 6:192. https://doi.org/10.3389/feart.2018.00192

Tanaka S (2007) Possibility of a low P-wave velocity layer in the outermost core from global SmKS waveforms. Earth Planet Sci Lett 259:486-499

Tarduno JA, Cottrell RD, Smirnov AV (2006) The Paleomagnetism of single silicate crystals: recording geomagnetic field strength during mixed polarity intervals, superchrons, and inner core growth. Rev Geophys 44:RG1002. https://doi.org/ 10.1029/2005RG000189

Tarduno JA, Cottrell RD, Davis WJ, Nimmo F, Bono RK (2015) A hadean to Paleoarchean geodynamo recorded by single zircon crystals. Science 349: 521-524

Watanabe K, Ohtani E, Kamada S, Sakamaki T, Miyahara M, Ito Y (2014) The abundance of potassium in the Earth's core. Phys Earth Planet Inter 237:6572. https://doi.org/10.1016/j.pepi.2014.10.001

Wicht J, Sanchez S (2019) Advances in geodynamo modelling. Geophys Astrophys Fluid Dyn 113:2-50. https://doi.org/10.1080/03091929.2019. 1597074

Yoshida S, Hamano Y (1993) The westward drift of the geomagnetic field caused by length-of-day variation, and the topography of the core-mantle boundary. Geophys J Int 114:696-710

Yukutake T, Shimizu H (2015) Drifting and standing field in the geomagnetic field for the past 400 years. Phys Earth Planet Inter 248:63-72

Yukutake T, Shimizu H (2016) On the latitude dependence of drift velocity of the geomagnetic main field and its secular variation. Phys Earth Planet Inter 257: 28-39

Ziegler LB, Stegman DR (2013) Implications of a long-lived basal magma ocean in generating Earth's ancient magnetic field. Geochem Geophys Geosyst 14: 4735-4742. https://doi.org/10.1002/2013GC005001

\section{Publisher's Note}

Springer Nature remains neutral with regard to jurisdictional claims in published maps and institutional affiliations. 